Research Article

\title{
Modelling Residential Building Costs in New Zealand: A Time-Series Transfer Function Approach
}

\author{
Linlin Zhao $\mathbb{D}^{1}{ }^{1}$ Jasper Mbachu, ${ }^{2}$ and Zhansheng Liu ${ }^{1}$ \\ ${ }^{1}$ College of Architecture and Civil Engineering, Beijing University of Technology, Beijing 100124, China \\ ${ }^{2}$ Faculty of Society and Design, Bond University, Gold Coast, Queensland QLD 4226, Australia \\ Correspondence should be addressed to Linlin Zhao; linlinsuc@sina.com
}

Received 4 June 2019; Revised 25 September 2019; Accepted 1 October 2019; Published 27 January 2020

Academic Editor: Ana C. Teodoro

Copyright (c) 2020 Linlin Zhao et al. This is an open access article distributed under the Creative Commons Attribution License, which permits unrestricted use, distribution, and reproduction in any medium, provided the original work is properly cited.

\begin{abstract}
Cost estimating based on a building cost index plays an important role in project planning and cost management by providing accurate cost information. However, an effective method to predict the building cost index of New Zealand is lacking. This study proposes a transfer function method to improve the forecasting accuracy of the building cost index. In this study, the New Zealand house price index is included in the transfer function models as an explanatory variable to produce cost forecasts. The proposed method is used to estimate the building cost index of residential buildings including one-story houses, two-story houses, and town houses in New Zealand. To demonstrate the effectiveness of the proposed method, this study compares the cost forecasts generated from the transfer function models and the autoregressive integrated moving average (ARIMA) models. The results indicate that the proposed transfer function method can achieve better outcomes than ARIMA models by considering the time-lag causality between building costs and New Zealand house prices. The proposed method can be used by industry professionals as a practical tool to predict project costs and help the professionals to better capture the inherent relationships between cost and house prices.
\end{abstract}

\section{Introduction}

In today's highly competitive market, companies are seeking effective methods to accurately predict project costs, since an accurate cost estimate is important to the commercial success of a project [1]. Project cost estimates are needed by clients, consultants, and contractors for purposes such as project feasibility studies, financial evaluation of alternatives, and the formulation of initial budgets and tender prices [2]. Accurate forecasting of a building project's cost is crucial to adequately managing resources [3]. Moreover, inaccurate cost estimates constitute one of the main reasons for project cost overruns [4]. The construction cost index has been widely used in the construction industry for generating cost estimates [5]. The cost index provides information regarding cost changes in the industry, which are caused by changes in the prices of materials, labour, and equipment. The construction cost index can reflect fluctuations in construction costs [6]. In fact, accurate prediction of the cost index plays an important role in preparing cost estimates [7, 8]. Moreover, understanding cost index trends, and the associated factors that influence these trends, allows industry professionals to properly perform the tasks of cost planning and management. Due to the importance of the cost index, exploring effective tools for forecasting changes in the cost index has prompted a large body of scholarly research.

Building costs in New Zealand increased considerably during the period 2002-2012 [9]. The fluctuations of cost index usually result in inaccurate estimations. As accuracy plays an important role in preparing budgets and bids in most building projects, industry professionals and organizations have long shown interest in finding an effective tool to accurately predict the building cost index. However, traditional approaches are often regarded as not effective [10]. The objective of this study is to provide a reliable forecasting tool for predicting the construction cost index. This study proposes a transfer function method to forecast the building cost index of New Zealand. The transfer 
function method incorporates the cost-influencing variables into the model to quantify their effect on the movement of the cost index.

Time-series analysis is a classic and powerful approach used in predicting the future of stochastic processes. The transfer function model is another method of time-series forecasting, incorporating more variables (including more predicting information) into the model for producing more accurate forecasts. ARIMA can only include the cost variable and its past values into the model, which ignores the fact that the variables can be influenced by other factors $[11,12]$. This is one of the main reasons why transfer function models can have comparative advantages over ARIMA models. This study takes into account the influence of house prices in a transfer function model for building cost forecasting. The proposed method was applied to forecast the cost index of residential buildings in New Zealand including one-story houses, two-story houses, and town houses. The ARIMA model was also used in forecasting to demonstrate the effectiveness of the proposed transfer function model.

The rest of this study is organized as follows: Section 2 discusses previously related works. Section 3 illustrates the proposed transfer function method and ARIMA model. Section 4 presents the application of the proposed method and ARIMA model to the cost series and the effectiveness assessment of the proposed transfer function method. The results are discussed in Section 5. Section 6 presents the conclusions of this study.

\section{Literature Review}

2.1. The Forecasting Methods. In the last few decades, several methods for deriving forecasting models of the construction cost index have been proposed. The most common used techniques include time-series analysis methods [13], causal methods [7, 14], artificial neutral network algorithms [2, 15], and case-based reasoning [16, 17]. Time-series analysis methods, including exponential smoothing, autoregressive and moving average, autoregressive integrated moving average (ARIMA), and seasonal ARIMA, have been widely used in the forecasting of time series $[18,19]$. Time-series analysis methods forecast future values based on past values and corresponding errors. Causal methods are based on the view that cause decides the effect and that future values can be predicted that are dependent on explanatory variables. Causal methods include Granger causality, multiple regression analysis, and cointegration [20]. Additionally, new prediction methods have been recently proposed, including artificial intelligent models [15], grey system [21], fuzzy sets, and evidence theory $[22,23]$.

The time-series analysis method has been used to predict changes in the construction cost index. This method analyzes index patterns from the past and then extrapolates these patterns into predictions of future trends [24]. Studies focusing on forecasting of the construction cost index were previously conducted. In study [5], univariate time-series models, such as Holt-Winter exponential smoothing method, simple moving average, ARMA, and ARIMA, were used to predict the construction cost index. Moreover, according to study [25], the ARIMA model is the best model for one-step-ahead predictions of the construction cost index (CCI), while Holt-Winter ES is suitable for making multiple-step-ahead predictions of the cost index.

In addition to the time-series analysis method, causal methods have been used to forecast the construction cost index. The principle of regression methods is that variation in the cost index is tightly related to other variables [12]. Hence, future values of the cost index can be obtained based on information provided by the predictive variables. Study [26] adopted an integrated regression model for predicting the construction tender price index. Study [8] employed a cointegrated vector autoregression model for predicting the construction cost index. Similarly, study [27] presented a regression model that incorporates economic and financial variables for forecasting movements of tender price in Hong Kong. Study [12] used a dynamic regression model that includes several economic indicators to predict cost fluctuation. The results demonstrated the effectiveness of the regression method as compared to other methods. In fact, the regression method builds relationships between the cost index and the variables that influence it. Hence, this method can evaluate causes of cost variations. Consequently, to develop effective risk strategies, industry professionals can evaluate the effects of the factors that influence project cost. In study [28], the vector error correction model (VECM) that incorporated the producer price index (PPI) was used to forecast the construction cost index. The results indicated that the VECM can provide accurate cost index forecasts. Additionally, study [12] employed a dynamic regression model to predict the cost index. Study [29] developed regression models for company-level cost flow forecasting. Study [30] presented a regression model for predicting costs of public building projects.

In study [31], three different methods were used to predict the cost index, which included exponential smoothing, multiple regressions, and artificial neutral networks (ANNs). The results indicated that the ANN method generated the least accurate forecasts. Study [32] concluded that the ANN model has the potential of predicting longterm forecasts. Recent studies have been performed in which two forecasting techniques were combined into one model. For example, study [33] used a forecast combination model that adaptively identifies the best forecast and optimizes various combinations of commonly used project cost forecasting models to improve the accuracy of project cost forecasts. Taking interests and benefits into account, accurate predictions and simple implementations are always required [13].

2.2. The Cost-Influencing Factor: House Price. Changes in some variables are usually influenced by changes in other variables; the latter variables are called leading indicators [34]. Leading indicators have been successfully used in forecasting. For example, in [35], the study used financial and economic indicators in forecasting US recessions. The application of leading indicators is based on the view that repetitive sequences occur in the business cycle. The cycles 
include booms and busts in various activities, but these booms and busts do not happen at exactly the same time for all economic activities; some activities are leading and some lagging. Although a leading indicators model is usually referred to as "a method without a theory," existing literature and empirical evidence give clues as to the selection of appropriate indicators.

In [36, 37], the studies pointed out that housing supply usually exhibits a lag. Therefore, house prices should influence future housing supply, since developers' decisions about whether to increase the housing supply frequently depend on present house prices. Based on the findings of [38], house prices affect changes in building construction costs through the effect of the derived demand for housing. Moreover, in [39], the study also provided evidence that building construction costs are sensitive to housing prices.

2.3. Gaps in the Literature. A construction cost index is usually used in cost estimates. To improve the accuracy of the cost estimates, several forecasting methods have been proposed to predict the construction cost index. Many studies have been conducted focusing on the forecasting of the cost index. The current study proposes the transfer function model to improve the forecasting accuracy of the building cost index of New Zealand. The method has never been used to forecast the cost index. Moreover, house price has been included into the transfer function model to improve the accuracy of cost forecasting. This study is the first that incorporates the time-lag causality between house price and building cost variables into the model in order to improve the forecasting accuracy.

When a time series is examined, questions usually arise about the relationship and impact of other series on it over time. If the relationship or impact is important, a dynamic model incorporating the relationship or impact is necessary. A transfer function model was introduced to relate the endogenous response series to the exogenous series. The transfer function model combines the advantages of univariate time-series analysis and causal methods, which considers the data-series pattern and incorporates exploratory variables into the model. Unlike the black box method such as artificial neutral networks (ANNs) and the method that is difficult to decide the model parameters like the vector error correction model (VECM), the transfer function method has mathematical function and crosscorrelation function can be used to decide the model parameters. Examples of transfer function applications abound in business, economics, and engineering. In business, it is used widely in modelling sales and advertising [40]. In economics, the transfer function was used for predicting business cycles. It has also modelled the effect of personal disposal income on real nondurable consumption in the UK [41]. According to [42], statistical and engineering process controls are associated with modelling the transfer functions between inputs and outputs. The transfer function method can be used as an effective tool for forecasting in many complicated situations.

\section{Methodology}

3.1. Data. The building cost index of residential buildings in New Zealand, including one-story houses, two-story houses, and town houses, was obtained from the QV cost builder. The building cost index (BCI) is defined as the average cost per square metre of the building. The BCI includes raw material costs, labour costs, and equipment costs. The building cost index of New Zealand, including residential buildings, commercial buildings, industrial buildings, and educational buildings, is published quarterly in New Zealand by the QV cost builder. The New Zealand house price index was employed in this study and obtained from the Reserve Bank of New Zealand. Changes in house prices can be measured in many ways. The house price index produced by the Reserve Bank of New Zealand has become a favoured benchmark in recent years. The 72 observations used were quarterly observations starting with the first quarter of 2001, through until the last quarter of 2018. The training sample is from 2001:Q1 to 2014:Q4 (totally 56 observations), while the validation sample is from 2015:Q1 to 2018:Q4. The four data series including the building cost index of the one-story house (HBC1), two-story house (HBC2), and town house (HBC3) and the house price index of New Zealand (AHP) are plotted in Figure 1. It is evident from the graph that the four data series are autocorrelated and highly unlikely stationary.

3.2. Seasonal ARIMA Model. The seasonal ARIMA model in its seasonal form is usually given as in equation (1), denoted as $\operatorname{ARIMA}(p, d, q)(P, D, Q)_{s} . p, d$, and $q$ refer to the autoregressive order, differencing order, and moving average term of the nonseasonal part of the model, respectively, while $P$, $D$, and $Q$ have the same role for the seasonal part of the model, and $s$ indicates the number of seasons.

$$
\varphi_{p}(B) \varnothing_{P}(B)(1-B)^{d}\left(1-B^{s}\right)^{D} z_{t}=\theta_{q}(B) \vartheta_{Q}(B) a_{t},
$$

where

$$
\begin{aligned}
\varphi_{p}(B) & =1-\varphi_{1} B-\varphi_{2} B^{2}-\cdots-\varphi_{p} B^{p}, \\
\theta_{q}(B) & =1-\theta_{1} B-\theta_{2} B^{2}-\cdots-\theta_{q} B^{q}, \\
\varnothing_{P}(B) & =1-\varnothing_{1} B^{s}-\varnothing_{2} B^{2 s}-\cdots-\varnothing_{P} B^{P s}, \\
\vartheta_{Q}(B) & =1-\vartheta_{1} B^{s}-\vartheta_{2} B^{2 s}-\cdots-\vartheta_{Q} B^{Q s}, \\
B z_{t} & =z_{t-1}, \\
B^{s} z_{t} & =z_{t-s},
\end{aligned}
$$

and $\varphi_{1}, \varphi_{2}, \ldots, \varphi_{p}$ are the parameters of the nonseasonal autoregressive terms of the model; $\theta_{1}, \theta_{2}, \ldots, \theta_{q}$ are the parameters of the nonseasonal moving average terms of the model; $\varnothing_{1}, \varnothing_{2}, \ldots, \varnothing_{P}$ are the parameters of the seasonal autoregressive terms of the model; $\vartheta_{1}, \vartheta_{2}, \ldots, \vartheta_{Q}$ are the parameters of the seasonal moving average terms of the model; $B$ is the backshift operator; $d$ and $D$ indicate regular and seasonal differencing, respectively; $a_{t}$ is a white noise process; and $z_{t}$ is the data series. 


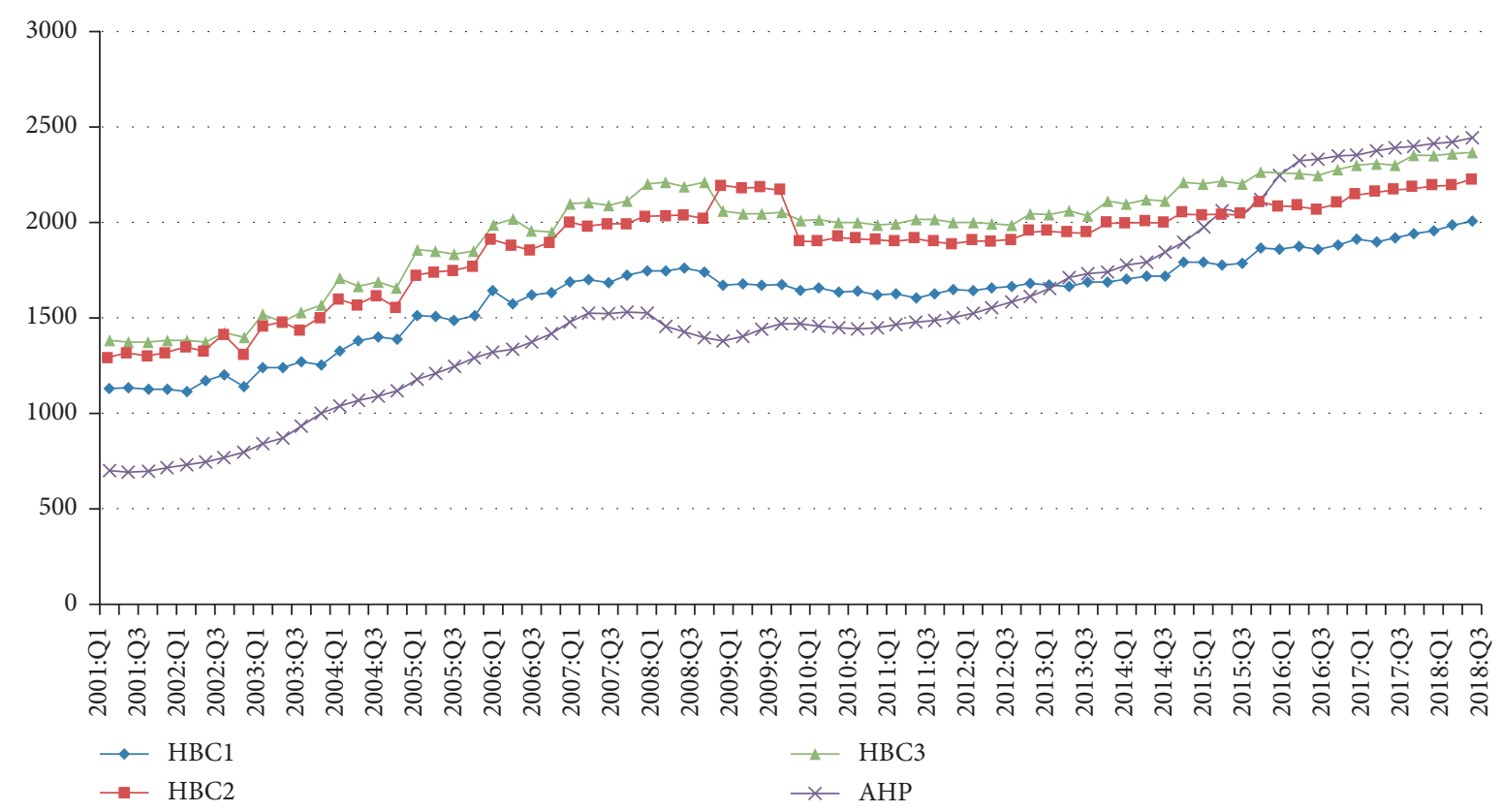

Figure 1: Time-series plots.

Autocorrelation function (ACF) and partial autocorrelation function (PACF) are usually used to identify an ARIMA model, providing systematic guidance about the underlying correlated behaviour of the series. In fact, the procedure follows five steps: (i) stationarity examination, (ii) model identification, (iii) parameter estimation, (iv) model verification, and (v) forecasting.

3.3. Transfer Function Method. The transfer function method combines time-series analysis and causal method [43]. It can obtain output variables based on input variables at different time periods [44]. The model development process is based on study [45].

The general transfer function is shown as

$$
z_{t}=\mu+\frac{C \omega(B)}{\delta(B)} B^{b} z_{t}^{(x)}+a_{t}
$$

where

$$
\begin{gathered}
\omega(B)=1-w_{1} B-w_{2} B^{2}-\cdots-w_{s} B^{s}, \\
\delta(B)=1-\delta_{1} B-\delta_{2} B^{2}-\cdots-\delta_{r} B^{r},
\end{gathered}
$$

and $z_{t}$ represents the stationary $Y_{t}$ values, $z_{t}^{(x)}$ represents the stationary $X_{t}$ values, $\mu$ is a constant term, $C$ is a scale parameter, $b$ is the order of delay that is the time delay between changes in $X_{t}$ and the impact on $Y_{t}, s$ is the order of regression, and $r$ represents the order of decay.

3.3.1. Stationary Transformation. If the time series is stochastic, the variables are usually centered or differenced to attain a condition of stationarity. In general, it is necessary to apply differencing to either the input series $z_{t}^{(x)}$ or the output series $z_{t}$ or both, in order to achieve stationarity [45]. Moreover, the input series $z_{t}^{(x)}$ or the output series $z_{t}$ does not need to be differenced in the same way. The ACFs of the data series are shown in Figure 2, which indicate they are nonstationary variables. Therefore, they need to be differenced to be a stationary variable for further modelling.

3.3.2. Prewhitening Time Series $z_{t}^{(x)}$ and $z_{t}$. It is recognised that autocorrelation in the input series may contaminate the cross-correlation between the input and output series [46]. Autocorrelation is a major reason for spurious relationships. For example, two unrelated time series that are internally autocorrelated, sometimes by chance, can produce significant cross-correlations. Thus, a prewhitening filter is suggested to neutralize this autocorrelation [47]. This filter can transform the input series into white noise. It is formulated from the ARIMA models. The first step in the prewhitening process is to select an ARIMA model describing the $z_{t}^{(x)}$ series. The ARIMA model to describe $z_{t}^{(x)}$ is expressed as

$$
\varphi_{p}(B) \varnothing_{P}\left(B^{L}\right) z_{t}^{(x)}=\theta_{q}(B) \vartheta_{Q}\left(B^{L}\right) \alpha_{t} \text {. }
$$

So

$$
\alpha_{t}=\frac{\varphi_{p}(B) \varnothing_{P}\left(B^{L}\right) z_{t}^{(x)}}{\theta_{q}(B) \vartheta_{Q}\left(B^{L}\right)} .
$$

This inverse filter developed from $X_{t}$ is then applied to the $Y_{t}$ series substituting $z_{t}$ for $z_{t}^{(x)}$ in the above equation. Then, $\beta_{t}$ is obtained as

$$
\beta_{t}=\frac{\varphi_{p}(B) \varnothing_{P}\left(B^{L}\right) z_{t}}{\theta_{q}(B) \vartheta_{Q}\left(B^{L}\right)} .
$$

3.3.3. Determining Model Orders. The order of $b, r$, and $s$ determines the structure of the transfer function. The 


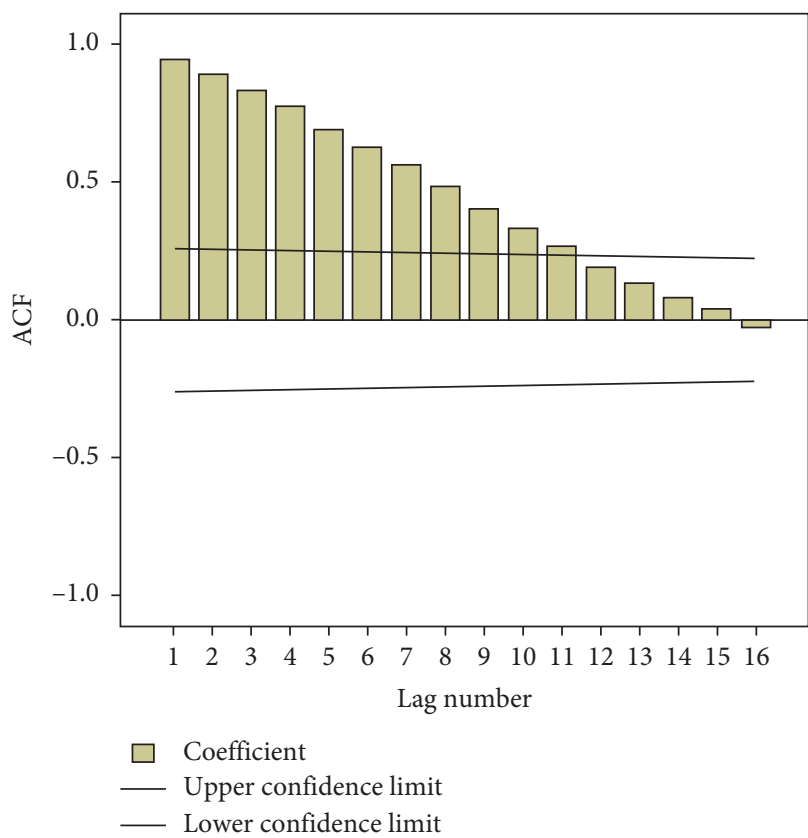

(a)

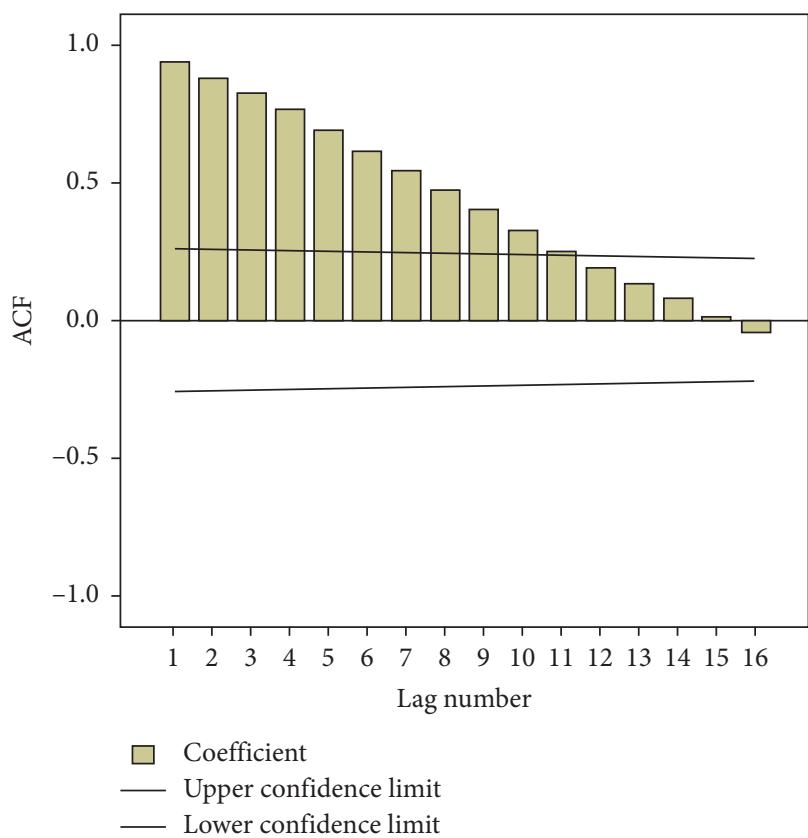

(c)

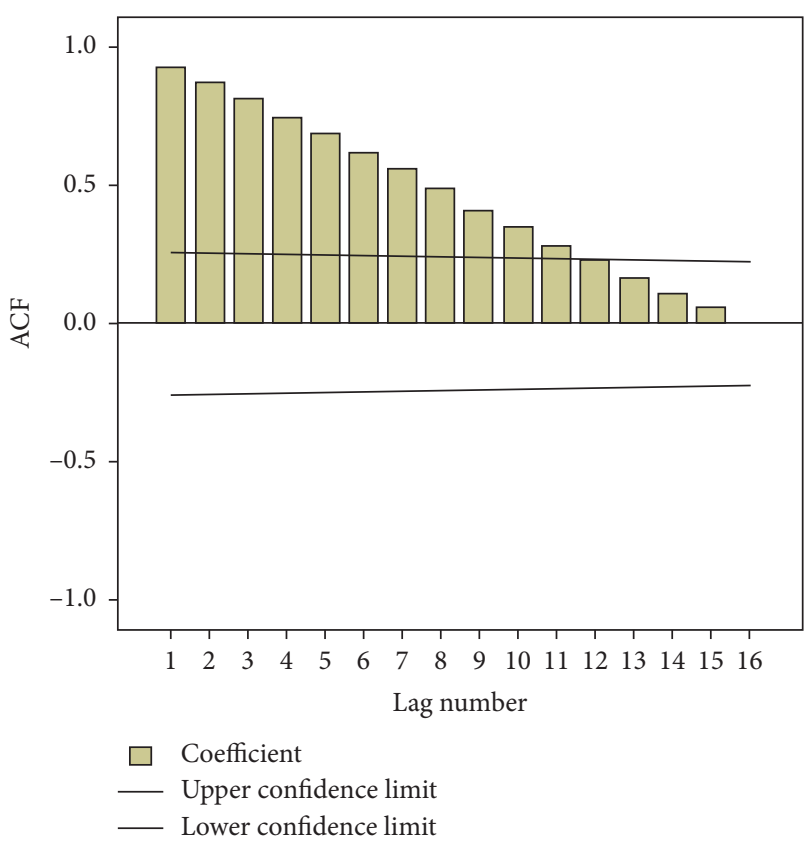

(b)

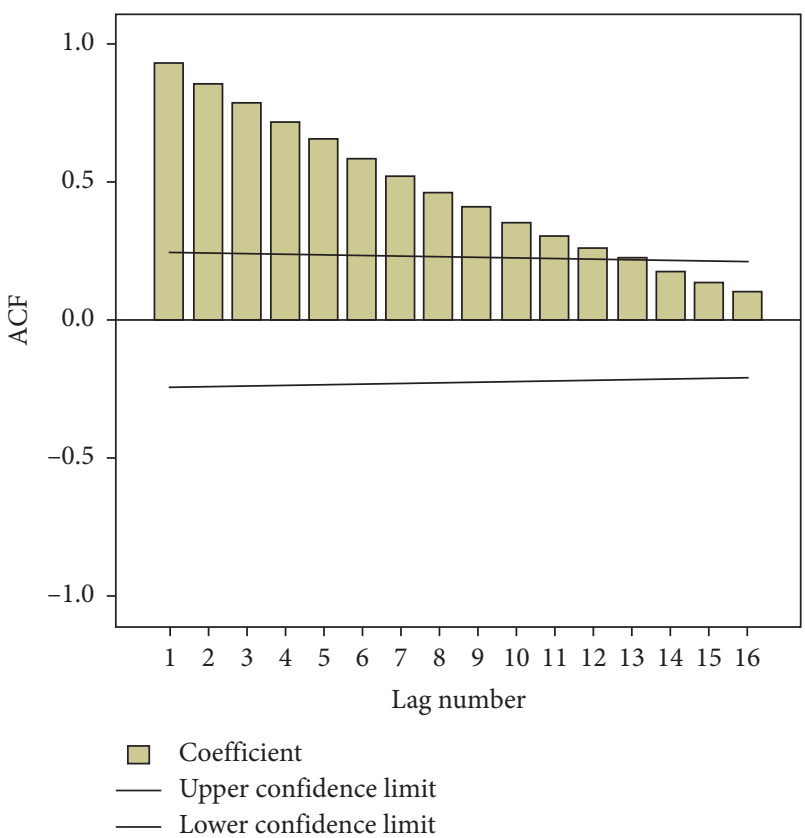

(d)

Figure 2: (a) ACF of HBC1; (b) ACF of HBC2; (c) ACF of HBC3; (d) ACF of AHP.

cross-correlation function between $\alpha_{t}$ and $\beta_{t}$ can be used to tentatively determine the model orders $b, s$, and $r$. The cross-correlation subjected to the identical transformation remains the same. After both $X_{t}$ and $Y_{t}$ series are prewhitened, direct estimation of the orders is made possible from the examination of the cross-correlation function (CCF) [45]. The shape of the cross-correlation between the two series explores the orders $(b, r$, and $s)$ of the transfer function. The cross-correlation function at lag $k$ can be described as

$$
r_{k}\left(\alpha_{t}, \beta_{t}\right)=\frac{\sum_{t=b}^{n-k}\left(\alpha_{t}-\bar{\alpha}\right)\left(\beta_{t+k}-\bar{\beta}\right)}{\left[\sum_{t=b}^{n}\left(\alpha_{t}-\bar{\alpha}\right)^{2}\right]^{1 / 2}\left[\sum_{t=b}^{n}\left(\beta_{t+k}-\bar{\beta}\right)^{2}\right]^{1 / 2}}
$$

where $\bar{\alpha}$ is the mean of $\alpha_{t}$ values and $\bar{\beta}$ is the mean of $\beta_{t}$ values.

To interpret the cross-correlation function (CCF), it is supposed that there are no spikes at negative lags. If there were, this indicates that $z_{t}$ has an effect on $z_{t}^{(x)}$. In that case, 
the transfer function cannot be used. There can be no feedback from $Y_{t}$ to $X_{t}$. In other words, $X_{t}$ in the transfer function model must be exogenous. One of the assumptions of the transfer function is that the relationship proceeds from $X_{t}$ to $Y_{t}$. A spike at negative lags can possibly occur, indicating a feedback, simultaneity, or a reverse effect. An apparent spike at negative lags may result from the failure to prewhiten that fails to trim out contaminating autocorrelation within the input series or may be due to the reverse effect or feedback in the relationship. No such spikes exist; the next step is to identify the lag at which the first spike occurs in the cross-correlation plot. This lag is $b$, the number of periods before $X_{t}$ begins to influence $Y_{t}$.

Furthermore, the practice has suggested that, after the first spike, a clear dying-down pattern (exponential or sinusoidal) may exist in the CCF. The value of $s$ is the number of lags that lie between the first spike and the beginning of the dying-down pattern. Sometimes, $s$ is not obvious due to the beginning of the dying-down pattern being questionable. In some cases, the value of $s$ is somewhat arbitrarily determined. In addition, the value of $r$ is determined by examining the dying-down pattern after lag $b+s$. Specifically, if the sample cross-correlation is dying down in an oscillatory or compound exponential fashion, it is reasonable to assign $r=2$. If it is dying down in a damped exponential fashion, it is reasonable to set $r=1$. The value of $r$ is zero if there is no decay. Fine tuning the identification process may require some trial and error with a view toward examining the parameters for significance and minimising the errors.

3.3.4. Estimation and Diagnosis Checking. After determining the values of $b, r$, and $s$, the model parameters can be estimated by least squares. To minimize sums of squared residuals, the iterations continue until they do not improve significantly. The next step is to evaluate the model adequacy by examining the model residuals. The residuals can be examined by their ACF and PACF as well as the Ljung-Box $Q$ test. The autocorrelation function and partial autocorrelation function of the residuals are employed. If no spikes exist in either residual autocorrelation function (RACF) or residual partial autocorrelation function (RPACF), it is reasonable to conclude that the residuals are independent which meets the model assumption [45]. Otherwise, if there are spikes in either RACF or RPACF, this indicates that residuals are dependent. New parameters should be incorporated into the model to account for those spikes.

A comparative evaluation of alternative models is necessary by examining the residuals or their error measures such as sums of squared residuals, mean absolute errors, and mean absolute percentage errors. The comparison also includes the evaluation of the forecasts produced by those models. The MAPE is usually employed for investigating the forecasts against the validation sample.

\section{Data Analysis}

The development process of ARIMA models and transfer function models for the building cost index and the forecasting performance of the models are discussed in this section. To compare the forecasting performance of proposed ARIMA models and transfer function models, the MAPE is introduced. It can be expressed as

$$
\text { MAPE }=\frac{\sum_{i=1}^{n}\left|\left(y_{i}-\hat{y}\right) / y_{i}\right|}{n} \times 100 \%,
$$

where $y_{i}$ is the actual observed value, $\hat{y}$ is the forecasting value, and $n$ is the number of forecasting values.

4.1. Seasonal ARIMA Model. The observations that are $s$ time intervals apart are similar if the seasonal period is $s$ [48]. In this study, $s=4$ quarters. Thus, for example, the observed value in the second quarter of one year will be alike to, or correlated with, that in the second quarter of the following year. However, it should be noted that the value in the second quarter is also correlated with that in the immediately preceding quarter, the first quarter. Therefore, there are two relationships going on simultaneously: (i) between observations for successive quarters within the same year and (ii) between observations for the same quarter in successive years. It is necessary to develop two time-series models-one for modelling the correlation between successive quarters within the years and one for describing the relationship between same quarters in successive years-and then combine the two. The model development process for seasonal models is similar to that used for regular time-series models. First, the difference operations can also be used to make time-series data stationary. For seasonal data, both regular difference and seasonal difference $\left(\nabla_{s} z_{t}=z_{t}-z_{t-s}\right)$ can be used.

4.1.1. ARIMA Model for Building Cost Index of One-Story House in New Zealand (HBC1). For the building cost data for the one-story house in New Zealand, denoted as HBC1, with quarterly seasonality, a regular first difference and a seasonal difference were applied: $\nabla \nabla_{4} z_{t}=\nabla\left(z_{t}-z_{t-4}\right)=$ $z_{t}-z_{t-1}-z_{t-4}+z_{t-5}$. Finally, when the data were differenced twice the autocorrelation function (ACF), it indicates that the data are stationary as the spikes fade out at both seasonal and nonseasonal lags, as shown in Figure 3(a). Having transformed the data to stationary, it is ready to identify the model. The patterns of the ACF and PACF shown in Figures 3(a) and 3(b) provide guidance to identify the stationary seasonal model. From Figure 3(a) showing the ACF for the stationary time series $\mathrm{HBC} 1$, it can be seen that there is a significant negative spike at lag 4 , after which the seasonal autocorrelation pattern cuts off. It indicates that a moving average model is applied to the four-quarter seasonal pattern. Moreover, it can also be seen that there is a significant autocorrelation at lag 1 and lag 3 , after which the ACF cuts off. This indicates the first-order and third-order moving average terms in the regular time-series model.

$\operatorname{ARIMA}(0,1,3)(0,1,1)_{4}$ was obtained to model the timeseries data HBC1. Moreover, the Ljung-Box chi-square statistics indicate that, for all lags, there is no significant autocorrelation remaining in the residuals, as shown in Figure 4(a). The residual tests confirm that the model 


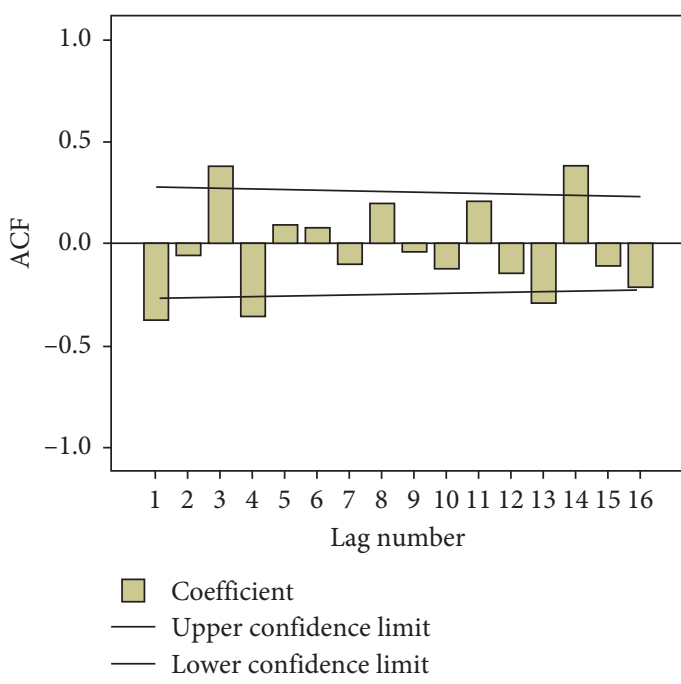

(a)

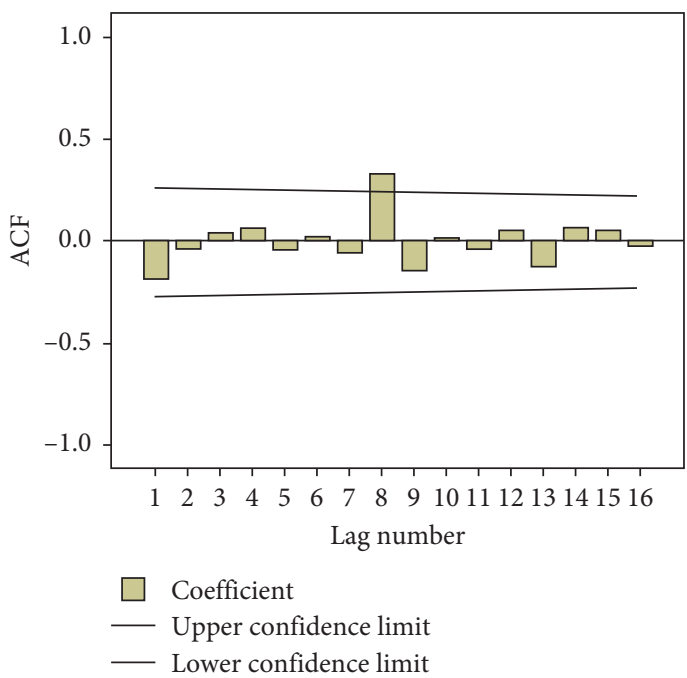

(c)

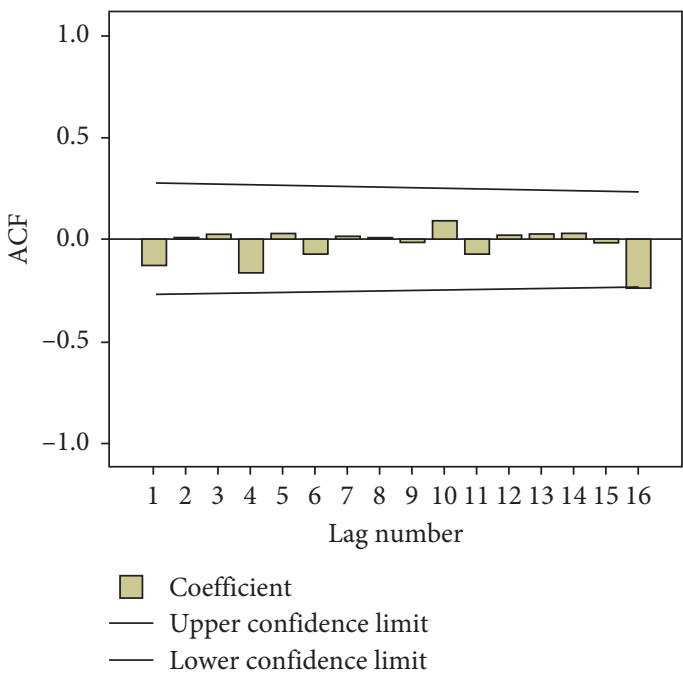

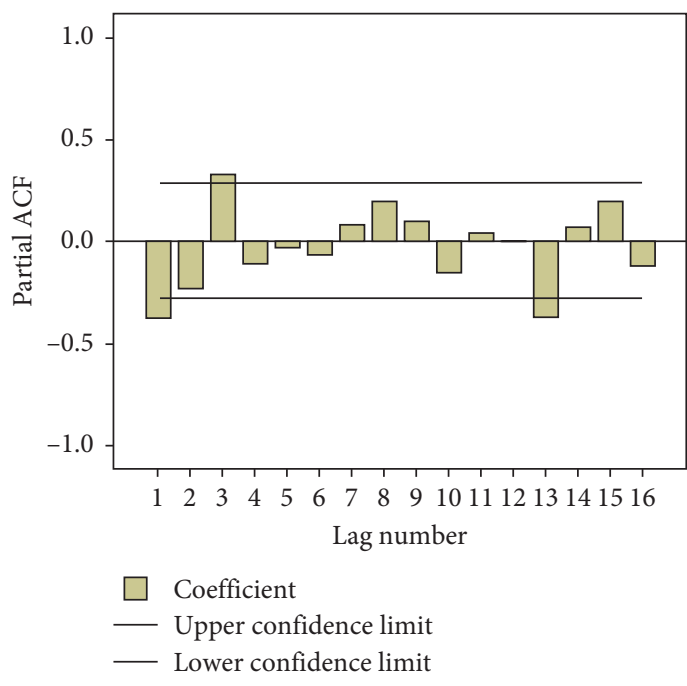

(b)

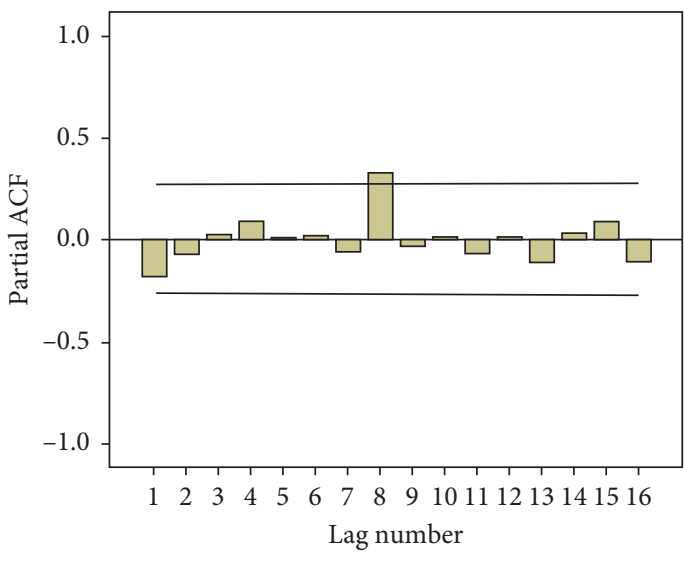

Coefficient

- Upper confidence limit

— Lower confidence limit

(d)

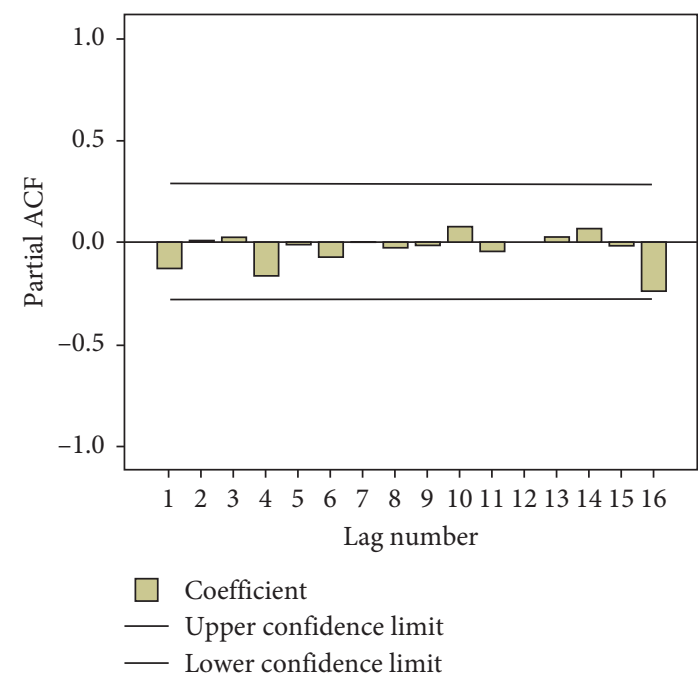

(f)

FIgURE 3: Continued. 


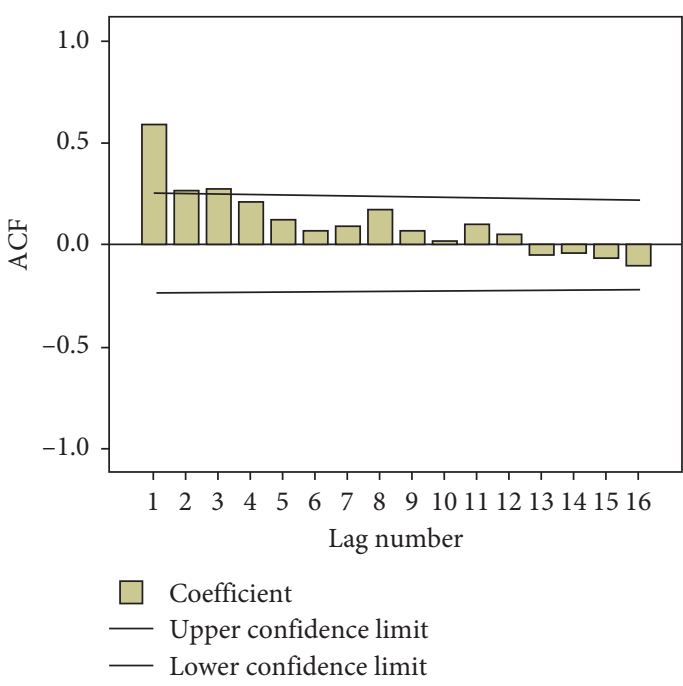

(g)

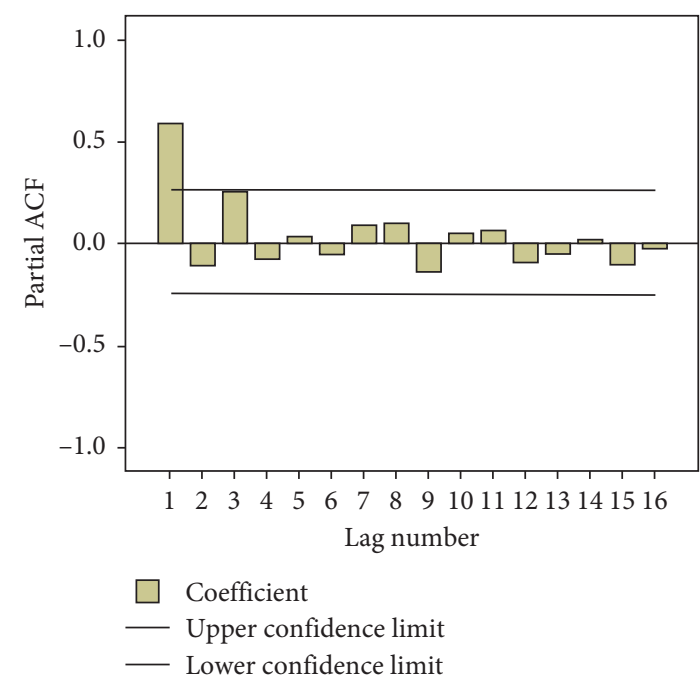

(h)

Figure 3: (a) ACF of stationary HBC1; (b) PACF of stationary HBC1; (c) ACF of stationary HBC2; (d) PACF of stationary HBC2; (e) ACF of stationary HBC3; (f) PACF of stationary HBC3; (g) ACF of stationary AHP; (h) PACF of stationary AHP.

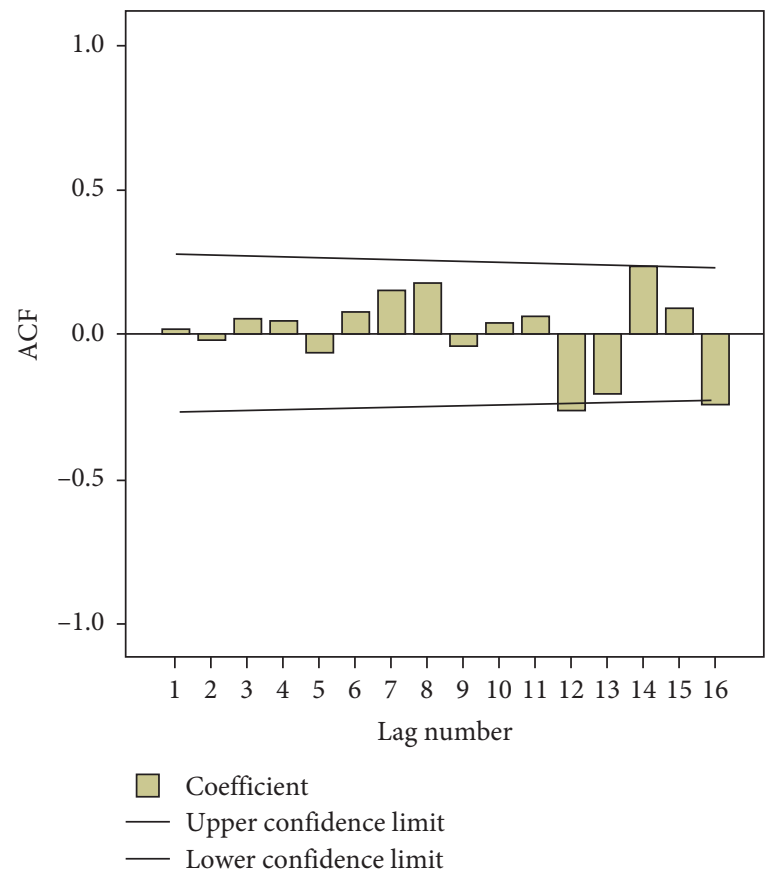

(a)

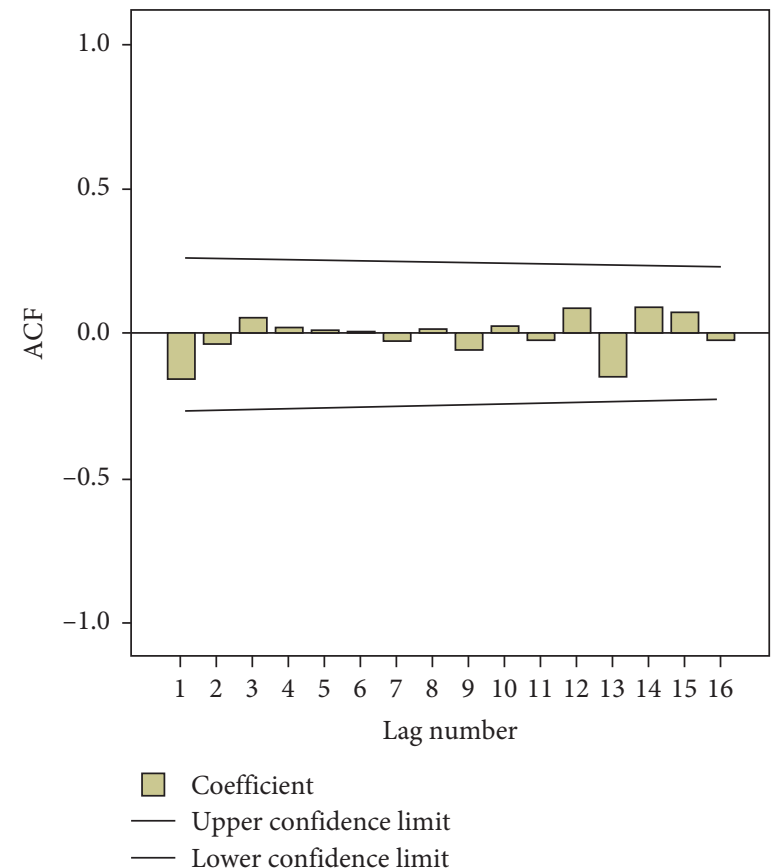

(b)

Figure 4: Continued. 


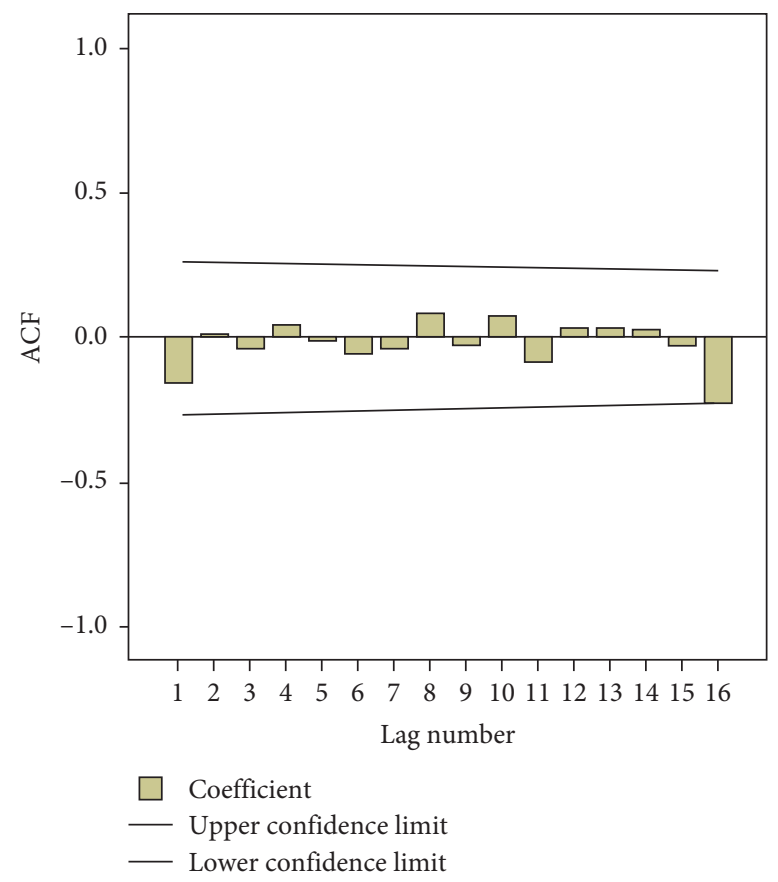

(c)

FIgURE 4: (a) ACF of the noise residuals of the ARIMA model for HBC1; (b) ACF of the noise residuals of the ARIMA model for HBC2; (c) ACF of the noise residuals of the ARIMA model for HBC3.

provides a fairly effective description of the dynamics in HBC1 data.

4.1.2. ARIMA Model for Building Cost Index of Two-Story House in New Zealand (HBC2). The building cost of a twostorey house in New Zealand is denoted as HBC2. Based on the ACF and PACF shown in Figures 3(c) and 3(d), the estimated seasonal ARIMA model for forecasting building cost of a two-storey house in New Zealand is found to be $\operatorname{ARIMA}(0,1,0)(0,0,2)_{4}$. The residuals shown in Figure 4(b) indicate that the model is adequate. The forecast error for two-year-ahead forecasts measured by the MAPE and RMSE is illustrated in Table 1. The values of the MAPE and RMSE are 2.177 and 61.76 , respectively.

4.1.3. ARIMA Model for Building Cost Index of Town House in New Zealand (HBC3). The building cost of a town house in New Zealand is denoted as HBC3. Seasonal ARIMA models are fitted to stationary building cost series of a town house, and the cost series require a regular difference and a seasonal difference to achieve stationarity. According to Figures 3(e) and 3(f), the seasonal ARIMA model is $\operatorname{ARIMA}(0,1,0)(1,0,0)_{4}$. The final ARIMA model estimated and selected for forecasting future building cost of a town house in New Zealand is ARIMA $(0,1,0)(1,0,0)_{4}$. The model is adequate and consistent with the underlying theory as the residuals shown in Figure 4(c).

4.2. Transfer Function Model. The transfer function models will be developed below. In all cases, only the first 56 observations were used, which indicates the data set up to 2014:Q4 were used to specify the models. Based on the approach in [45], the transfer function model can be identified. After some initial analysis, the New Zealand house price series (AHP) was used as the input variable. The ACF and PACF of AHP are shown in Figures 3(g) and 3(h). Using the proposed identification method, the ARIMA model for New Zealand house price (AHP) can be expressed as

$$
(1-0.827 B)\left(X_{t}-X_{t-1}\right)=a_{t}
$$

The model residuals were checked for independence. There is no significant autocorrelation at the $5 \%$ level. The results of the transfer function models for the residential building costs in New Zealand are shown in Table 2.

4.2.1. Transfer Function Model for Building Cost Index of One-Story House in New Zealand. Building cost index of a one-storey house in New Zealand, denoted as HBC1, could be influenced by the New Zealand house prices. Building costs and house prices are positively correlated so that an increase in house prices leads to an increase in the building costs, and vice versa. Thus, finding a mathematical relationship between these two variables in the transfer function form can be particularly valuable. The preliminary identification of series with the ACF and PACF to test for stationarity and seasonality was performed. With the observation of slow damping of the ACF correlogram, the regular first differencing and seasonal differencing of order four were required to bring about stationarity. After regular 


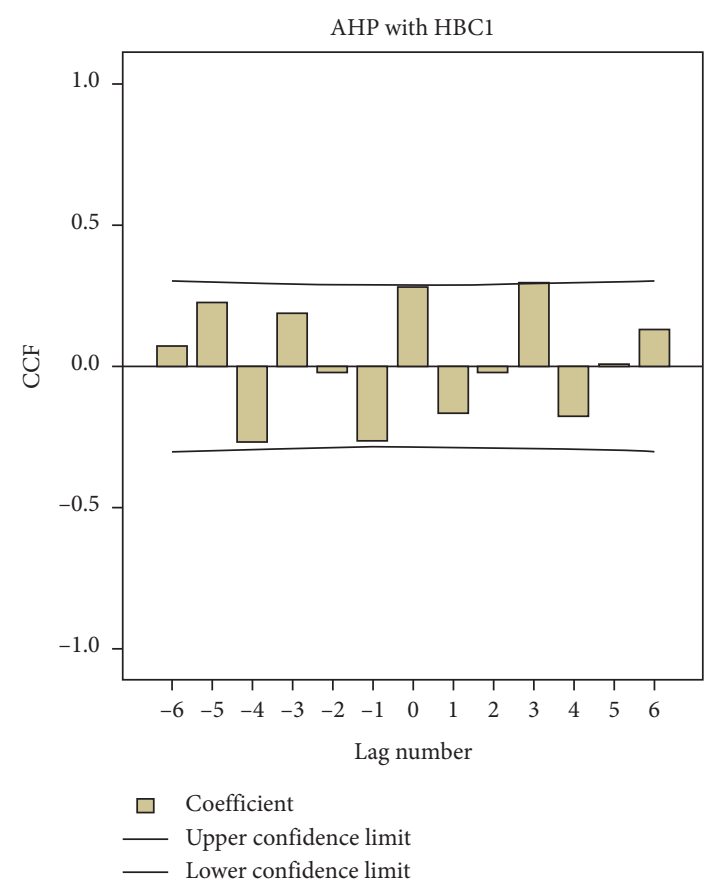

(a)

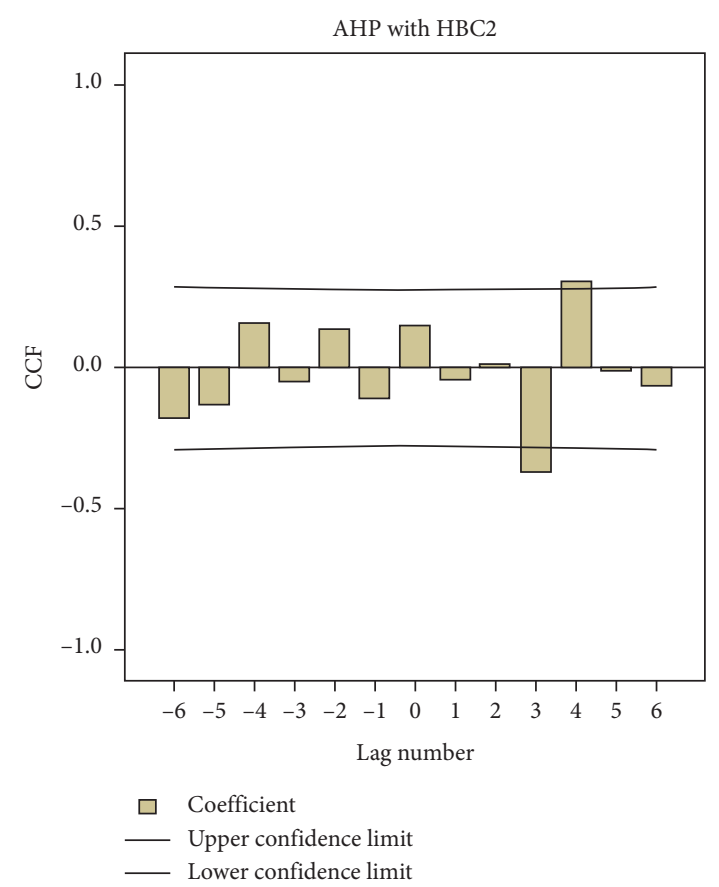

(b)

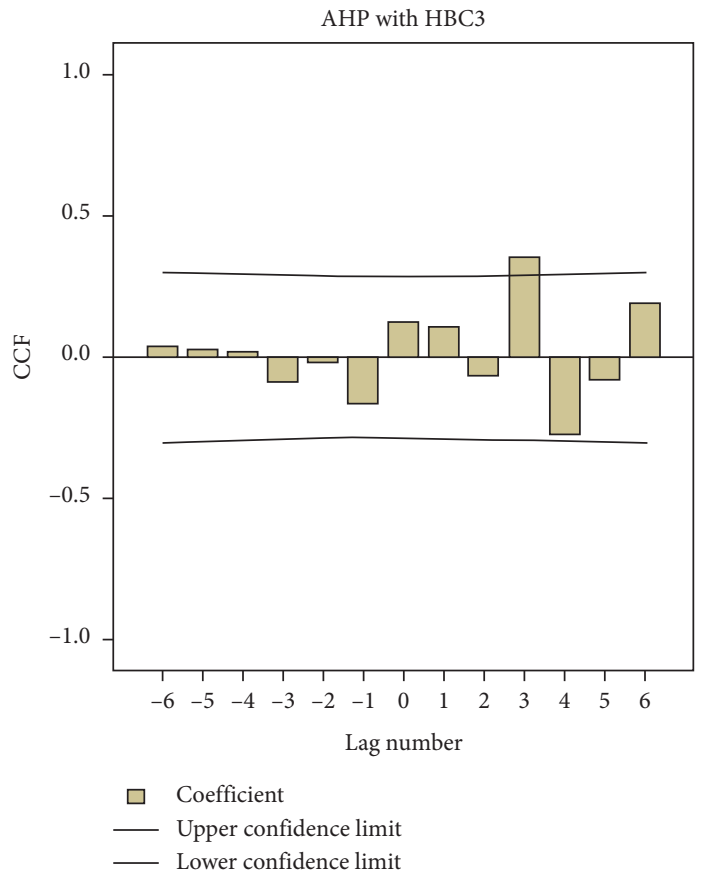

(c)

Figure 5: (a) CCF of AHP and HBC1; (b) CCF of AHP and HBC2; (c) CCF of AHP and HBC3.

to bring about stationarity. After the first regular differencing of $\mathrm{HBC} 2$ series, the series is stationary.

First, this ARIMA model was used to filter the building cost for a two-storey house. Then, the cross-correlation between these two prewhitened series was computed, as shown in Figure 5(b). The first significant spike appears at lag 3. The orders of the transfer function $b=3, s=1$, and $r=1$ can be identified. The ordinary least-square method was used to estimate the model parameters. The transfer function is shown as

$$
z_{t}^{\mathrm{HBC} 2}=\frac{-1.341(1+1.257 B)}{1-0.429 B} B^{3} z_{t}^{(\mathrm{AHP})}+a_{t} .
$$

The model residuals should be examined to meet the assumption of error independence. According to Figures 6(c) and 6(d), it can be inferred that the residuals are 


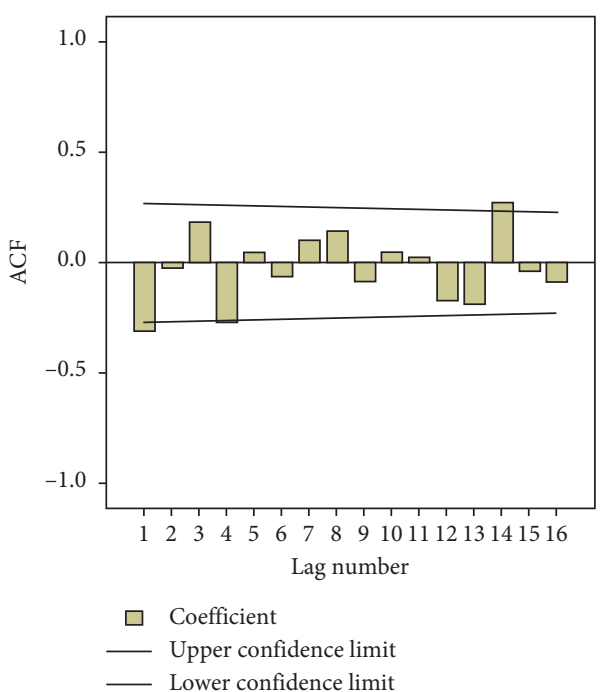

(a)

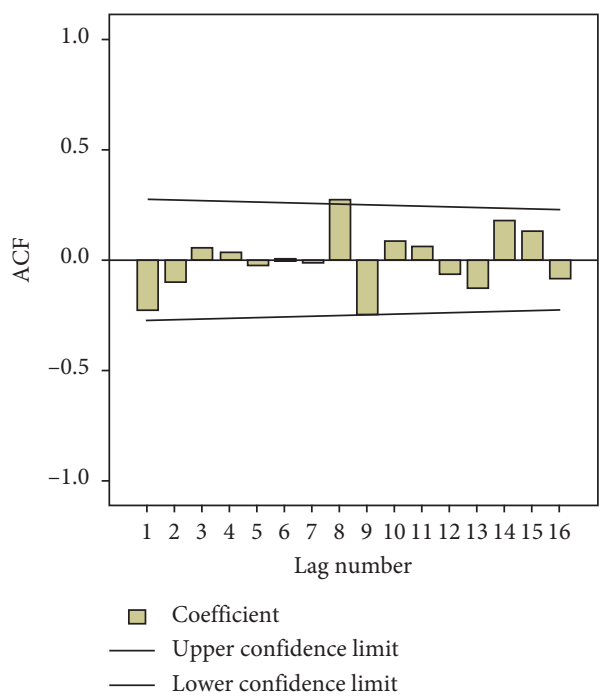

(c)

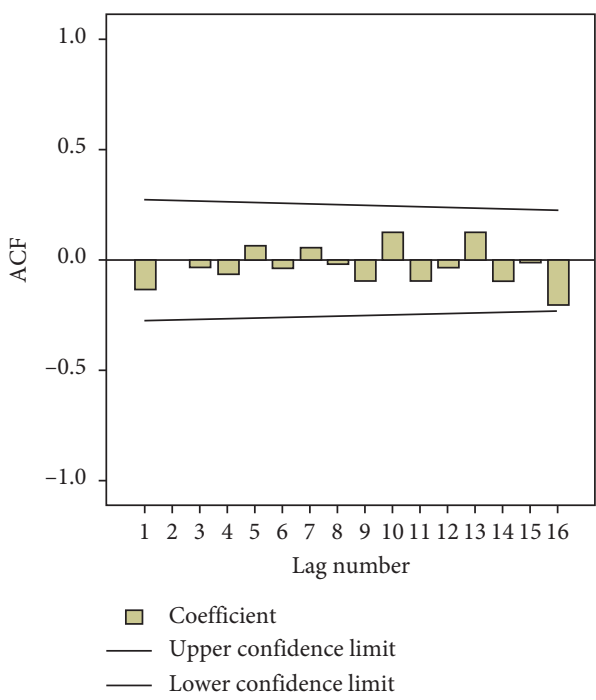

(e)

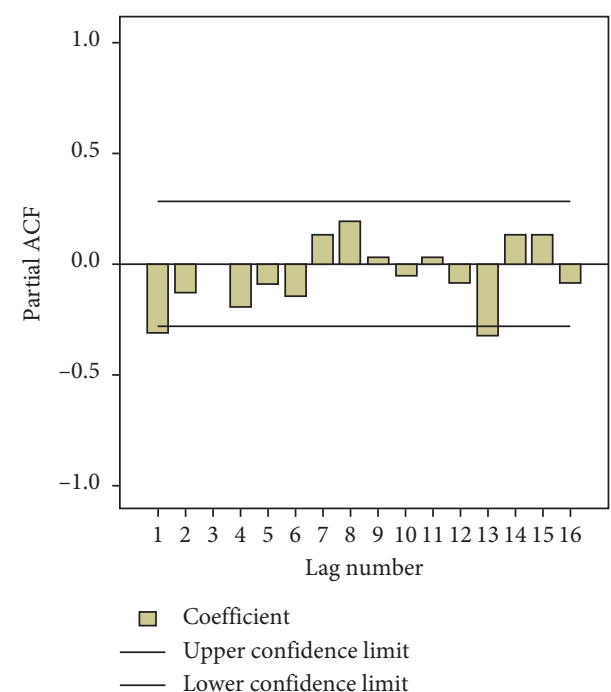

(b)

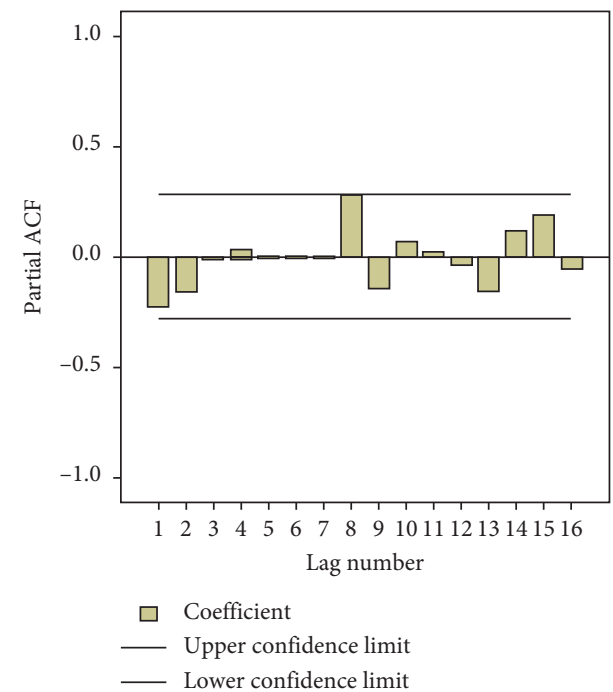

(d)

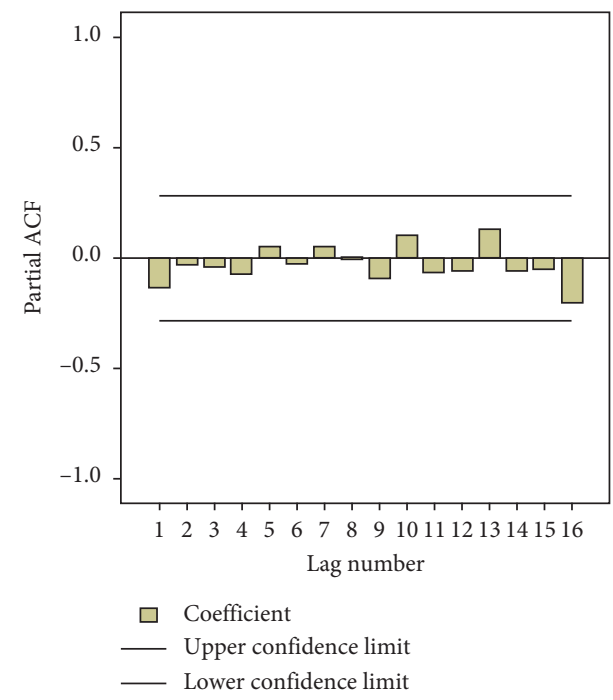

(f)

Figure 6: (a) ACF of the noise residuals of the transfer function model for HBC1; (b) PACF of the noise residuals of the transfer function model for HBC1; (c) ACF of the noise residuals of the transfer function model for HBC2; (d) PACF of the noise residuals of the transfer function model for HBC2; (e) ACF of the noise residuals of the transfer function model for HBC3; (f) PACF of the noise residuals of the transfer function model for HBC3. 


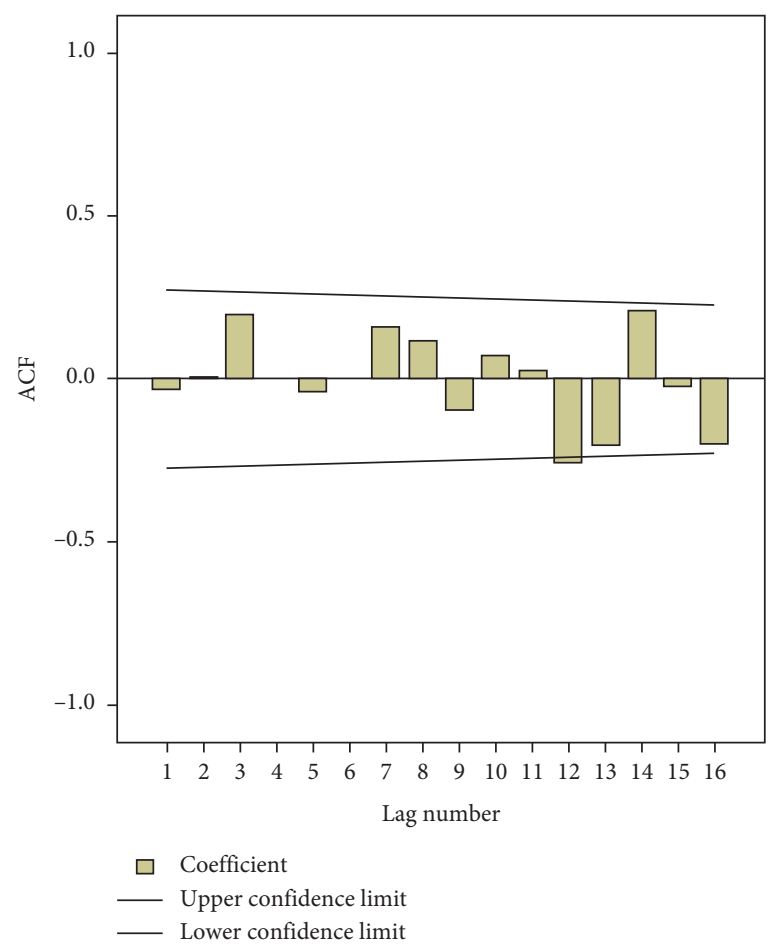

(a)

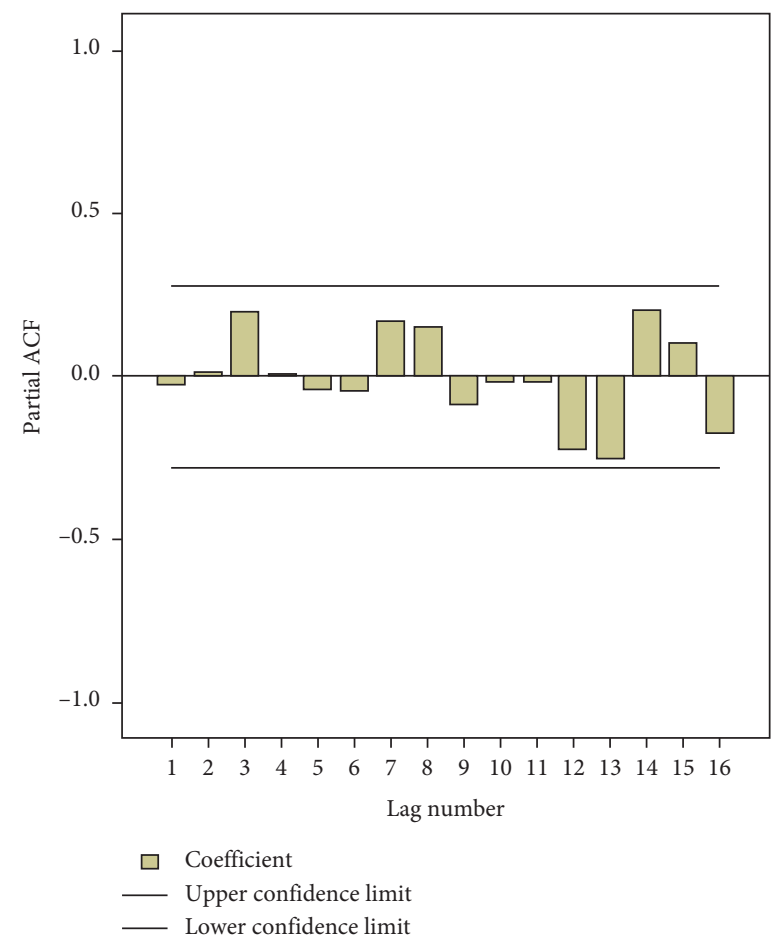

(b)

Figure 7: (a) ACF of the noise residuals of the remodel for HBC1; (b) PACF of the noise residuals of the remodel for HBC1.

a white noise process. The residuals shown in Figures 6(c) and $6(\mathrm{~d})$ suggest that the residuals are white noise. Moreover, the results of the Ljung-Box test also indicate the absence of the autocorrelation in the residuals. Therefore, the model in equation (13) is adequate.

4.2.3. Transfer Function Model for Building Cost Index of Town House in New Zealand. Building cost of a town house in New Zealand is denoted as HBC3. With the observation of slow damping of the ACF correlogram, the regular first differencing and seasonal differencing of order four were required to bring about stationarity. After regular and seasonal differencing of the $\mathrm{HBC} 3$ series, the series is stationary as shown from the ACF. In the identification of the transfer function model, it is necessary to apply the same prewhitening transformation to both the input and output series. Thus, the ARIMA model for house price (AHP) is also applied to the building cost series of a town house. However, before the prewhitening progress, the cost series has been transformed to stationary by a regular difference and a seasonal difference.

Figure 5(c) shows the first significant spike is at lag 0 on the cross-correlation function, indicating no delay time. The orders of the transfer function $b=3, s=0$, and $r=2$ can be identified. The ordinary least-square method was used to estimate the model parameters. The transfer function is shown as

$$
\begin{aligned}
z_{t}^{\mathrm{HBC} 3} & =\frac{C}{\left(1-\delta_{1} B-\delta_{2} B^{2}\right)} B^{3} z_{t}^{(\mathrm{AHP})}+a_{t} \\
& =\frac{0.089}{\left(1-1.614 B+0.849 B^{2}\right)} B^{3} z_{t}^{(\mathrm{AHP})}+a_{t} .
\end{aligned}
$$

The residuals were checked for autocorrelation and the chi-square values for all the lags were found to be not significant at the 5\% level, as shown in Figures 6(e) and 6(f). This suggests that the model residuals do not have problems with autocorrelation and, indeed, white noise.

4.3. Forecast Evaluation. The above proposed models were evaluated for their out-of-sample forecasting performance. The models were developed using data from 2001:Q1 to 2014:Q4, and then forecasts were made for the following 16 quarters (2015:Q1-2018:Q4). The model comparison was carried out in a meaningful and systematic way. The MAPE values for the transfer function models and seasonal ARIMA models for the period 2015:Q1-2018:Q4 are presented in Table 3. The results clearly indicate that the transfer function method outperforms the seasonal ARIMA models for all building cost series considered. The improvement of forecasting accuracy from the adoption of the transfer function model is best illustrated by observing the error measurements. For the building cost index of a one-story house (HBC1) in New Zealand, there is a reduction of about $39.1 \%$ 
TABLE 3: Comparison of model performance (MAPE).

\begin{tabular}{lcr}
\hline Cost series & ARIMA & TF \\
\hline HBC1 & 2.091 & 1.273 \\
HBC2 & 2.935 & 1.365 \\
HBC3 & 5.766 & 1.161 \\
\hline
\end{tabular}

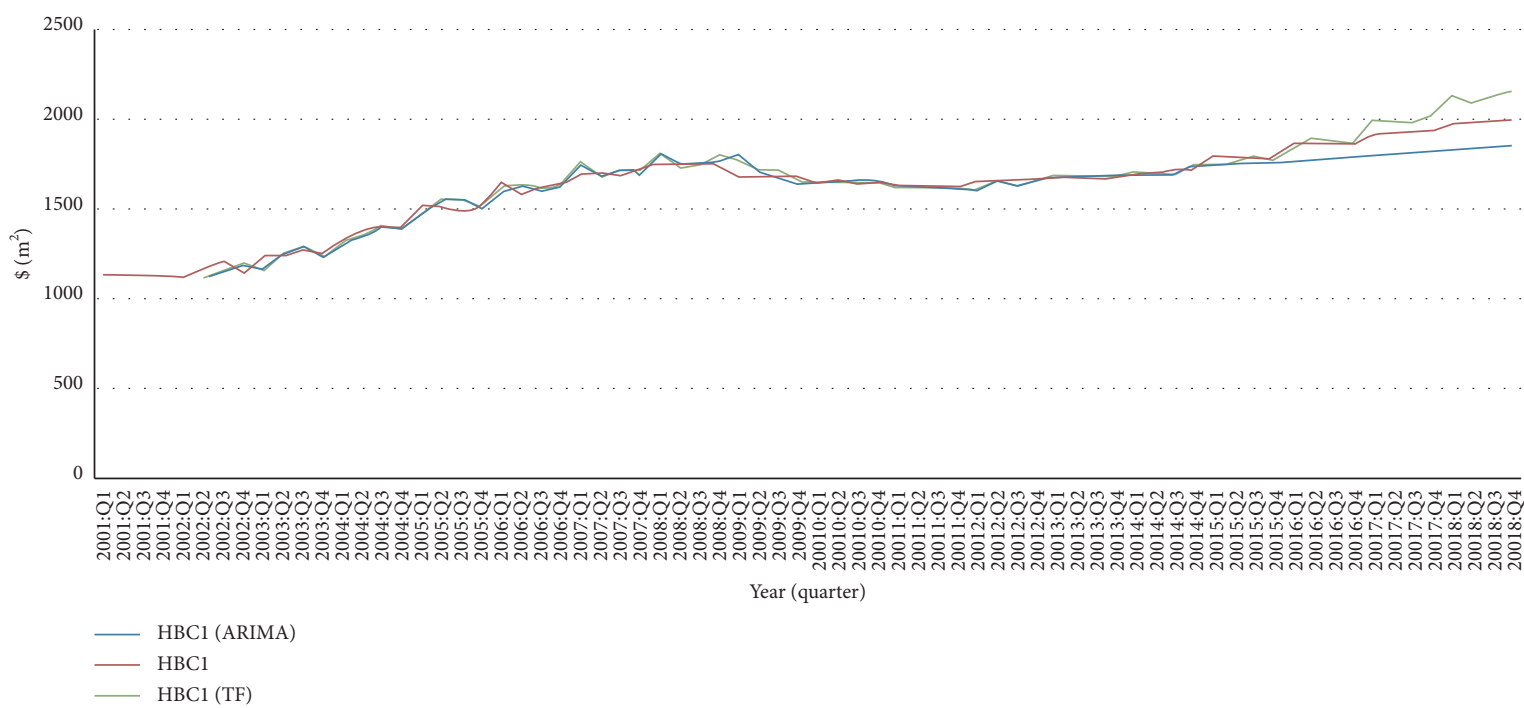

(a)

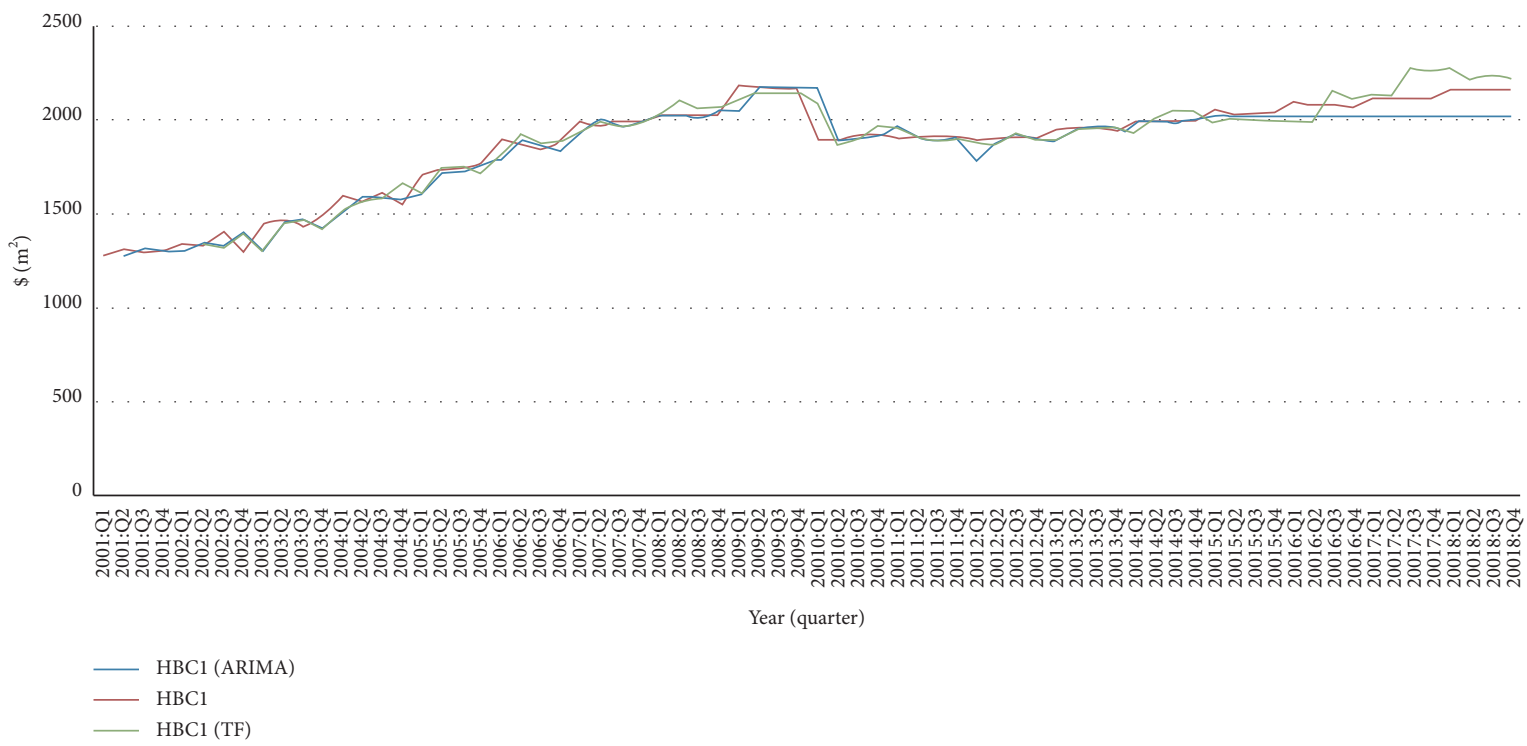

(b)

Figure 8: Continued. 


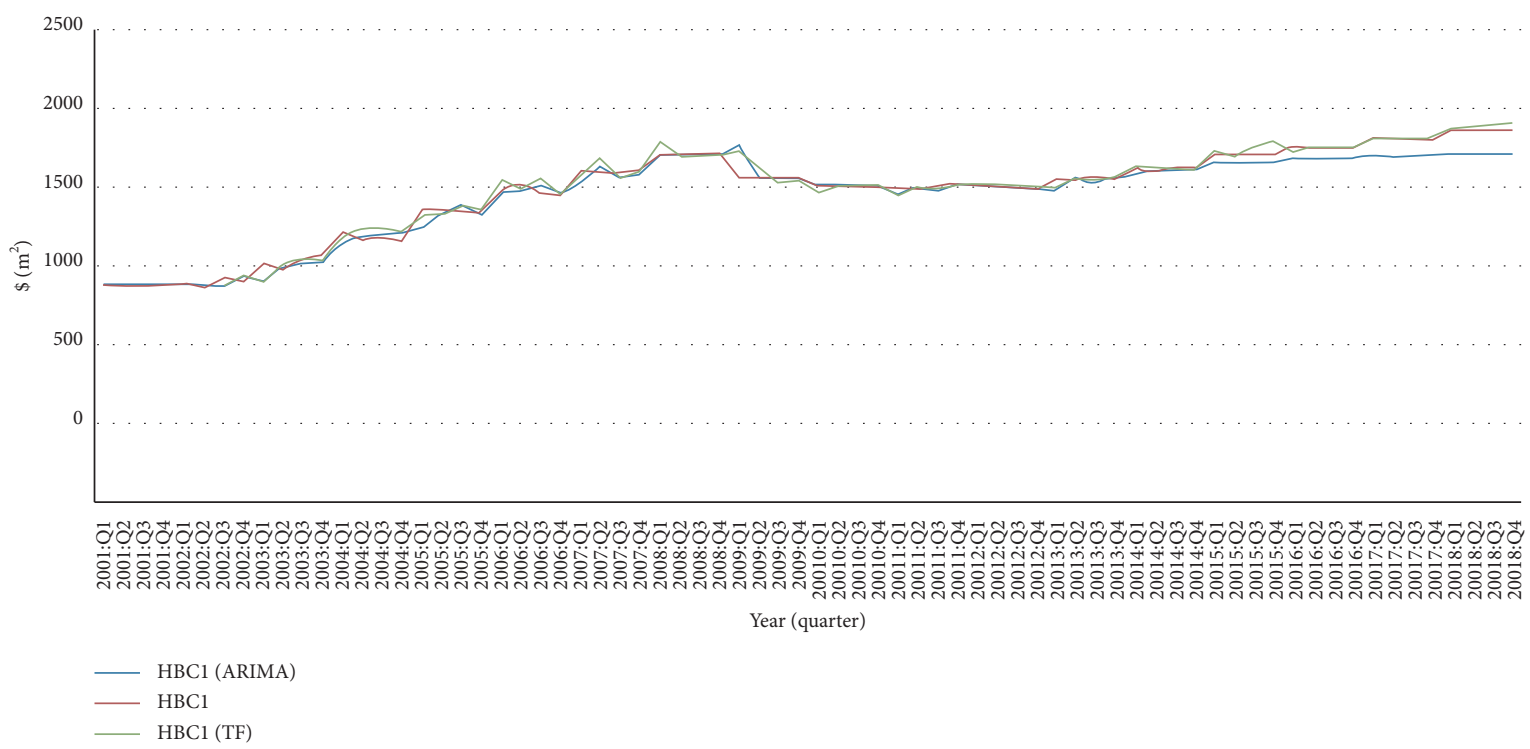

(c)

FIGURE 8: (a) Building cost index of $\mathrm{HBC1}$ and its forecasts generated from ARIMA and transfer function models; (b) building cost index of $\mathrm{HBC} 2$ and its forecasts generated from ARIMA and transfer function models; (c) building cost index of HBC3 and its forecasts generated from ARIMA and transfer function models.

in the MAPE from the seasonal ARIMA model to the transfer function model. For the building cost index of a two-story house in New Zealand (HBC2), the reduction from using the transfer function model is even more pronounced: there is a 53.5\% reduction in the MAPE from the ARIMA model to the transfer function model. For the building cost index of a town house in New Zealand (HBC3), the transfer function model provides a 79.9\% MAPE reduction over the seasonal ARIMA model. Note that the transfer function models are, for all three cost series, superior to the seasonal ARIMA models. The building cost index of $\mathrm{HBC} 1, \mathrm{HBC} 2$, and $\mathrm{HBC} 3$ and their forecasts generated from ARIMA and transfer function models are shown in Figure 8.

\section{Results and Discussion}

The fluctuations in the building cost index are problematic for cost estimation. The ARIMA models completely take into account the dynamic process of cost series, the seasonality, and the serial correlation in the residuals to obtain precise cost forecasts. Although the model can dynamically describe the time-series data, it cannot investigate the causality between independent variables and dependent variables. Based on the current state of knowledge and the existing literature, building costs are influenced not only by the construction industry but also by other factors, such as house prices, economic conditions, population, incomes, and business loans. The inclusion of explanatory variables into the models can forecast building cost more accurately. The New Zealand house price index was selected as an explanatory variable for predicating building cost in this study.

The analysis results suggest that the simplest model is not always the most appropriate one for predicting, particularly when additional information is available. Univariate models like ARIMA can be used as a benchmark in comparing forecasting performance. When explanatory variables are available, they can be included in the model to improve forecasting accuracy. Multivariate models can then be realised to improve forecasting performance. The transfer function model can describe more about the characteristics of the output than a univariate model by describing the dynamic relationship between the input and output variables. Inclusion of New Zealand house prices in the transfer function models significantly improves forecasting accuracy. This is consistent with the findings of [49], which indicated that model inclusion of an exogenous variable can improve the forecasting performance. Housing is one kind of building construction product that connects the building construction sector to the housing sector. So, the building costs are subject to changes in house prices. New Zealand house prices stimulate the changes in building costs, although building costs are usually viewed as fundamentals. The findings are also supported by the studies of $[38,50]$.

\section{Conclusion}

This study proposed the transfer function method to forecast the building cost index of New Zealand to improve the accuracy of the cost estimates that help in developing accurate budgets and preventing under- or overestimation. An ARIMA model was also used as a benchmark method. Based on the Box-Jenkins model development process, transfer function models and seasonal ARIMA models for building cost indices of one-storey houses, two-storey houses, and town houses in New Zealand were developed. The effectiveness of the transfer function models was compared with that of the univariate ARIMA models. The results indicated 
that the predictive accuracy of the transfer function model is superior to that of the ARIMA model, since the transfer function model achieved lower MAPE and RMSE.

The transfer function model was developed from a fusion of time-series analysis, regression analysis, and cross-correlation analysis. Cross-correlation analysis was used to explore the potential optimal parameters. Time-series analysis was used to identify the cost index patterns. Regression analysis was utilized to identify the underlying mapping between influencing factors and the cost index. The transfer function models that contain an exogenous variable (more information) are better at forecasting than the simpler ARIMA models. The causality between building cost and house prices was modelled in the transfer function method. The inclusion of house prices in the model significantly reduces the forecasting error of the transfer function models, relative to seasonal ARIMA models. This study has shown that the inclusion of an explanatory variable input within the framework leads to an improvement in forecasting performance.

This study makes important contributions to three areas. The main contribution of this study is to enhance cost estimation accuracy and guide industry practitioners in the preliminary design stage. The proposed transfer function model can be a useful tool for industry professionals to generate cost estimates that can help in pricing, bidding, and assessing construction projects. Second, the inclusion of New Zealand house prices in the transfer function model significantly improves the cost forecasting performance. The findings indicate that the inclusion of cost-influencing factors into the model can significantly improve the forecasting accuracy of the building cost index of New Zealand. The findings contribute to the present body of knowledge on cost estimation and may serve as a valuable guide for future model development. Third, the results of this study prove that New Zealand house price is a significant influencing factor of residential building cost. The results also demonstrate that variations in house prices can result in fluctuations in residential building costs. The results may help industry professionals understand the underlying relationship between the construction industry and housing market of New Zealand.

The developed models are based on the building cost index of New Zealand. However, the model development process can be used in other regions. The accuracy of longterm forecasting of the cost index using the transfer function model may be impaired due to uncertainty in the dynamic environment. Hence, the use of intelligent methods for longterm prediction of the cost index is a future research direction.

\section{Abbreviations}

ACF: Autocorrelation function

AHP: House price index of New Zealand

ANNs: Artificial neutral networks

ARIMA: Autoregressive integrated moving average

ARMA: Autoregressive moving average

BCI: Building cost index
CCF: Cross-correlation function

CCI: Construction cost index

ES: $\quad$ Exponential smoothing

HBC1: Building cost index of a one-story house in New Zealand

HBC2: Building cost index of a two-story house in New Zealand

HBC3: Building cost index of a town house in New Zealand

MAPE: Mean absolute percentage error

PACF: Partial autocorrelation function

PPI: $\quad$ Producer price index

RACF: Residual autocorrelation function

RMSE: Root mean square error

RPACF: Residual partial autocorrelation function

UK: United Kingdom

VECM: Vector error correction model.

\section{Data Availability}

The data used to support the findings of this study are available from the corresponding author upon request.

\section{Conflicts of Interest}

The authors declare no conflicts of interest.

\section{Authors' Contributions}

L. Z. and J. M. conceptualized the idea. L. Z. performed the methodology, prepared the original draft, and acquired the fund. Z. L. developed the software. L. Z. and Z. L. performed validation. J. M. supervised the work and reviewed and edited the paper.

\section{Acknowledgments}

This research was funded by the China Scholarship Council through the research project (grant no. 201206130069), Massey University (grant no. 09166424), and Beijing University of Technology (grant no. 004000514119067). The APC was funded by the three grants. The authors would like to thank the Reserve Bank of New Zealand and Ministry of Business, Innovation and Employment for providing data to conduct this research. In addition, the authors would like to thank all practitioners who contributed to this project.

\section{References}

[1] J. Gido and J. P. Clements, Successful Project Management, Cengage Learning, Stamford, CT, USA, 6th edition, 2015.

[2] R. Sonmez, "Conceptual cost estimation of building projects with regression analysis and neural networks," Canadian Journal of Civil Engineering, vol. 31, no. 4, pp. 677-683, 2004.

[3] Y. Takano, N. Ishii, and M. Muraki, "Determining bid markup and resources allocated to cost estimation in competitive bidding," Automation in Construction, vol. 85, pp. 358-368, 2018.

[4] E. W. Merrow, Concepts, Strategies and Practices for Success, John Wiley \& Sons, Hoboken, NJ, USA, 2011. 
[5] B. Ashuri and J. Lu, "Time series analysis of ENR construction cost index," Journal of Construction Engineering and Management, vol. 136, no. 11, pp. 1227-1237, 2010.

[6] Y. Elfahham, "Estimation and prediction of construction cost index using neural networks, time series, and regression," Alexandria Engineering Journal, vol. 58, no. 2, pp. 499-506, 2019.

[7] S. Hwang, "Dynamic regression models for prediction of construction costs," Journal of Construction Engineering and Management, vol. 135, no. 5, pp. 360-367, 2009.

[8] J. X. Xu and S. Moon, "Stochastic forecast of construction cost index using a cointegrated vector autoregression model," Journal of Management in Engineering, vol. 29, no. 1, pp. 10-18, 2013.

[9] MBIE, NZ Sector Report 2013-Construction, Ministry of Building Innovation and Employment, Wellington, New Zealand, 2013.

[10] A. Jrade, A Conceptual Cost Estimating Computer System for Building Projects, Concordia University, Montreal, Canada, 2000.

[11] M.-Y. Cheng and A. F. V. Roy, "Evolutionary fuzzy decision model for cash flow prediction using time-dependent support vector machines," International Journal of Project Management, vol. 29, no. 1, pp. 56-65, 2011.

[12] S. Hwang, "Time series models for forecasting construction costs using time series indexes," Journal of Construction Engineering and Management, vol. 137, no. 9, pp. 656-662, 2011.

[13] R. Zhang, B. Ashuri, Y. Shyr, and Y. Deng, "Forecasting construction cost index based on visibility graph: a network approach," Physica A: Statistical Mechanics and Its Applications, vol. 493, pp. 239-252, 2018.

[14] D. J. Lowe, M. W. Emsley, and A. Harding, "Predicting construction cost using multiple regression techniques," Journal of Construction Engineering and Management, vol. 132, no. 7, pp. 750-758, 2006.

[15] H.-L. Yip, H. Fan, and Y.-H. Chiang, "Predicting the maintenance cost of construction equipment: comparison between general regression neural network and Box-Jenkins time series models," Automation in Construction, vol. 38, pp. 30-38, 2014.

[16] G. Morcous, H. Rivard, and A. M. Hanna, "Case-based reasoning system for modeling infrastructure deterioration," Journal of Computing in Civil Engineering, vol. 16, no. 2, pp. 104-114, 2002.

[17] N.-J. Yau and J.-B. Yang, "Case-based reasoning in construction management," Computer-Aided Civil and Infrastructure Engineering, vol. 13, no. 2, pp. 143-150, 1998.

[18] R. G. Brown, Smoothing, Forecasting and Prediction of Discrete Time Series, Courier Dover Publications, Mineola, NY, USA, 2004.

[19] G. P. Zhang and M. Qi, "Neural network forecasting for seasonal and trend time series," European Journal of Operational Research, vol. 160, no. 2, pp. 501-514, 2005.

[20] B. Pfaff, Analysis of Integrated and Cointegrated Time Series with R, Springer, Berlin, Germany, 2008.

[21] Y.-H. Lin and P.-C. Lee, "Novel high-precision grey forecasting model," Automation in Construction, vol. 16, no. 6, pp. 771-777, 2007.

[22] H. Zheng, Y. Deng, and Y. Hu, "Fuzzy evidential influence diagram and its evaluation algorithm," Knowledge-Based Systems, vol. 131, pp. 28-45, 2017.

[23] X. Zhou, X. Deng, Y. Deng, and S. Mahadevan, "Dependence assessment in human reliability analysis based on D numbers and AHP," Nuclear Engineering and Design, vol. 313, pp. 243-252, 2017.

[24] M.-Y. Cheng, N.-D. Hoang, and Y.-W. Wu, "Hybrid intelligence approach based on LS-SVM and differential evolution for construction cost index estimation: a Taiwan case study," Automation in Construction, vol. 35, pp. 306-313, 2013.

[25] B. Ashuri, S. M. Shahandashti, and J. Lu, "Empirical tests for identifying leading indicators of ENR construction cost index," Construction Management and Economics, vol. 30, no. 11, pp. 917-927, 2012.

[26] S. T. Ng, S. O. Cheung, M. Skitmore, and T. C. Y. Wong, "An integrated regression analysis and time series model for construction tender price index forecasting," Construction Management and Economics, vol. 22, no. 5, pp. 483-493, 2004.

[27] J. M. W. Wong and S. T. Ng, "Forecasting construction tender price index in Hong Kong using vector error correction model," Construction Management and Economics, vol. 28, no. 12, pp. 1255-1268, 2010.

[28] S. M. Shahandashti and B. Ashuri, "Forecasting engineering news-record construction cost index using multivariate time series models," Journal of Construction Engineering and Management, vol. 139, no. 9, pp. 1237-1243, 2013.

[29] H. L. Chen, "Developing cost response models for companylevel cost flow forecasting of project-based corporations," Journal of Management in Engineering, vol. 23, no. 4, pp. 171-181, 2007.

[30] A. Hammad, S. Ali, G. J. Sweis, and R. J. Sweis, "Statstical analysis on the cost and duration of public building projects," Journal of Management in Engineering, vol. 26, no. 2, pp. 105-113, 2010.

[31] W. P. Trefor, "Predicting changes in predicting changes in construction cost indexes using neural networks," Journal of Construction Engineering and Management, vol. 120, no. 2, pp. 306-320, 1994.

[32] G.-H. Kim, S.-H. An, and K.-I. Kang, "Comparison of construction cost estimating models based on regression analysis, neural networks, and case-based reasoning," Building and Environment, vol. 39, no. 10, pp. 1235-1242, 2004.

[33] K. Byung-Cheol and H. K. Young, "Improving the accuracy and operational predictability of project cost forecasts: an adaptive combination approach," Production Planning \& Control, vol. 29, no. 9, pp. 743-760, 2018.

[34] N. Kulendran and S. F. Witt, "Leading indicator tourism forecasts," Tourism Management, vol. 24, no. 5, pp. 503-510, 2003.

[35] M. Qi, "Predicting US recessions with leading indicators via neural network models," International Journal of Forecasting, vol. 17, no. 3, pp. 383-401, 2001.

[36] M.-C. Chen and I.-C. Tsai, "A cobweb theory of house price incorporating investor behavior," Academia Economic Papers, vol. 35, pp. 315-344, 2007.

[37] J. Janssen, B. Kruijt, and B. Needham, "The honeycomb cycle in real estate," The Journal of Real Estate Research, vol. 9, pp. 237-251, 1994.

[38] I.-C. Tsai, "Housing supply, demand and price: construction cost, rental price and house price indices," Asian Economic Journal, vol. 26, no. 4, pp. 381-396, 2012.

[39] T. Sunde and P.-F. Muzindutsi, "Determinants of house prices and new construction activity: an empirical investigation of the Namibian housing market," The Journal of Developing Areas, vol. 51, no. 3, pp. 390-407, 2017.

[40] S. Makridakis, S. C. Wheelwright, and V. McGee, Forecasting: Methods and Applications, Wiley, Hoboken, NJ, USA, 2nd edition, 1983. 
[41] T. C. Mills, Time Series Techniques for Economists, Cambridge University Press, New York, NY, USA, 1990.

[42] G. E. P. Box, G. M. Jenkins, and G. C. Reinsel, Time Series Analysis: Forecasting and Control, Wiley, Hoboken, NJ, USA, 1994.

[43] Y. Hasanah, M. Herlina, and H. Zaikarina, "Flood prediction using transfer function model of rainfall and water discharge approach in Katulampa dam," in Proceedings of the 3rd International Conference on Sustainable Future for Human Security SUSTAIN 2012, pp. 317-326, Kyoto, Japan, November 2012.

[44] T. Cook, "An application of the transfer function to an economic-base model," The Annals of Regional Science, vol. 13, pp. 81-92, 1979.

[45] G. E. P. Box and G. M. Jenkins, Time Series Analysis: Forecasting and Control, Holden Day, Inc., San Francisco, CA, USA, 1976.

[46] R. Yaffee and M. McGee, Introduction to Time Series Analysis and Forecasting with Applications of SAS and SPSS, Academic Press Inc., Cambridge, MA, USA, 2000.

[47] G. E. Box, G. Jenkins, and G. Reinsel, Time Sereis Analysis, Wiley, Hoboken, NJ, USA, 4th edition, 2008.

[48] S. Bisgaard and M. Kulahci, Time Series Analysis and Forecasting by Example, John Wiley \& Sons, Inc, Hoboken, NJ, USA, 2011.

[49] R. Ashley, "On the usefulness of macroeconomic forecasts as inputs to forecasting models," Journal of Forecasting, vol. 2, no. 3, pp. 211-223, 1983.

[50] A. Grimes and A. Aitken, "Housing supply, land costs and price adjustment," Real Estate Economics, vol. 38, no. 2, pp. 325-353, 2010. 